\title{
Research on Teaching Mode of College English Translating Course from the Perspective of Eco- translatology
}

\author{
Zhai Man \\ School of Foreign Languages \\ Jilin Business and Technology College \\ Changchun, China \\ zhaiman@126.com
}

\begin{abstract}
As a subsidiary discipline of translation theory, eco-translatology cultivates translating behavior from the perspectives of integral correlation, macroscopic arrangement and multi-dimensional adaptation. This theory is proposed by Pro. Hu Gengshen originally, and emphasizes multi-dimensional adjustment of lingual dimension, cultural dimension and communicative dimension. Due to the limitation and high requirement about interpreting test, English examination adopts pure translating test to measure students' translation levels instead of interpreting check. Translation course has played more and more significant role in college English course on reading and writing. Eco-translatology theory is utilized in college translation teaching in order to equip students with new understanding of translation standard and distinct insight on meaning for betterment both in teaching effect and translating ability.
\end{abstract}

Keywords-eco-translatology; college English translating course; teaching mode; multi-dimensional adjustment; selection

\section{INTRODUCTION}

As a means for the studying on translation methods, ecotranslatology has interdisciplinary features obviously. It adopts the theory of adaptation and selection to make translators accommodate the interpretive discourse environment independently from the view of macroscopic eco-rationalism. Scholars consider it as a new well-rounded research paradigm aiming on discussing texts' ecology, translative environment and interrelation among translating groups. With the professional and specialized development of translation course, translating instruction has played a spectacular role, even stood out as an independent college course in traditional college English teaching ${ }^{[3]}$. This is a trend which would be bound to persist and even accelerate. In fact, although both teachers and students devote a great amount of vigor, time and concentration, there turn to be no anticipative effect shown by the deficiency of translating output and defectiveness on translating abilitypromotion.

Eco-translatology emphasizes entirety which involves correlation and mutual impaction. Correspondingly, this kind of entirety-oriented methodology can be used for directing college English translating portion in reading and writing course. Just profiting from the diversified unification and multi-dimensional transformation of eco-translatology, college translation class could train students' translating behavior into an organic, hierarchical and interconnected order. Under the guidance of eco-translatology, students are capable of getting rid of the confine in traditional translating strategy and making great breakthroughs on the barriers of angular translating rules of traditional college English courses. The core ideas of ecotranslatology are pursuing dynamic balance and mutual adaptation in translating process, which provides college students with vivid understanding and effective approach to translation.

With the ceaselessly improvement of eco-translatology and deeply investigation of college teaching mode, the relationship and cooperation mechanism among inner elements and segments of teaching could be understood by students more clearly ${ }^{[10]}$. Meanwhile, when each link of teaching and whole translated text combines, while isolated translating output mixes with dynamic guiding ideology, the real promotion in skill and profession of college students could be seen remarkably.

At present, translation teaching tends to undertake solely from translation theory and education theory, but fails in analyzing issues from aspects of integer macrocosm and systematisms ${ }^{[6]}$. Teachers are always lack of explicit purpose in translating branch, and ask-answer model is the only mode for instruction. Consequently, students just make sense of individual text rather than comprehend translating skill during college English class. The exuberant and powerful ecotranslatology theory provides both teachers and students a new and beneficial method for college translation teaching.

\section{OVERVIEWS ON ECO-TRANSLATOLOGY}

\section{A. Cores of Eco-translatology}

Translation is not only a language transforming behavior, but also a kind of cultural transplanting ${ }^{[1]}$. Eco-translatology gets rid of barriers on traditional translating rules, and provides a fresh visual angle for gaining insight into college translation reaching.

As a dominant component of eco-translatology, relevance and integrity are regarded as the emphasis of sub eco-system. 
Eco-translatology proposes that it is lack of relevance with traditional translating approaches in college teaching, moreover, the text's eco-environment should catch more concentration by interpreters ${ }^{[4]}$. In order to adopt the context's eco-environment, translating course in college tends to show more instruction about dynamic options at different degrees to college students. For example, the interrelationships among culture, author, reader and convention ought to be taken into consideration ${ }^{[8]}$. Therefore, in college translating courses, teachers had better lead in corresponding background information on culture, religion, society, history and so on. No other than explicit comprehension on the relevance and integrity of translating, college students could achieve better understanding on translating strategy and gain an accurate guideline for translating.

1) Multi-dimensional Transformation: First of all, lingual dimension stresses that translator should adjust the eco-lingual environment both source language and target language, and select the transformation about different lingual forms during translating. The operations belonging to this surface are often very elaborate and careful through words, grammar even speech sounds ${ }^{[2]}$. Secondly, cultural dimension refers to that translator should concentrate on the delivery and interpretation of cultural connotation. Because source language and target one belong to different cultures, translator ought to notice the transformation to cultural elements and atmosphere [5], meanwhile, avoid ambiguity and obscurity. Thirdly, communicative dimension points that translation should show the communicative purpose effectively, analyze people's relationship and emotional tendency.

2) Adaptation and Selection: The core of eco-translatology is a combination between adaptation and selection, which abides by original language eco-system. It asserts that translator's subjective initiative should be exploited adequately, but it doesn't stress on translator's self-awareness excessively. Appropriate selection and adjustment keep the two languages in a dynamic balance state during translating. As a translator, the student plays double-roles dynamically, bearing the constraint of translating eco-environment, at the same time, operating the output under subjective selection and adjustment.

\section{B. Evaluation and Development}

In recent years, Eco-translatology develops very fast in a steady and continuous step. Benefited in the cross-subjects character, a variety of aspects has developed evidently, such as theoretical construction, talents cultivation, academic exploitation, team integration, international exchange, base construction and so on. It can be seen easily that ecotranslatology provides a new view for studying. Many researchers use framework of eco-translatology to study and explore new modes for different disciplines. A great deal of papers, dissertations and monographs have published publicly.

\section{STUDY ON TEACHING MODE OF COLLEGE TRANSLATING COURSE UNDER FRAMEWORK OF ECO-TRANSLATOLOGY}

\section{A. Construction of Eco-environment in College Translation Teaching}

According to eco-translatology theory, translating ecoenvironment stands for the totality of external elements that affect translating subject's survival and development. Therefore, translating teaching eco-environment could be considered as an overall situation supporting every teaching segment. In other words, it is a kind of relationship among learners, tutors, teaching assistant, teaching content and teaching eco-environment. In addition to internal resources in college, there are huge numbers of external internet resources which could compensate the limitation in time and information of college course. The inter-communication among leaners, teachers, course resource and cognitive tools tends to be more and more significant in eco-interaction. In eco-translatology class, tutors and students ought to take steps into ecotranslating teaching and adjust rhyme of marching, then keep dynamic balance.

1) Selection on Texts: In eco-translatology system, no matter from single word to sentence or the opposite order, the words, sentences and texts are mutual influenced. Hence, text is the most ideal object for translating directly. It cannot realize integral function by analyze individual word, sentence, paragraph or even passage, because translating embodies crosslanguage, cross-culture and cross-space discourse transformation. To encourage students apply materials in usual lives to exhibit authenticity. Teachers also can choose text in accordance with students' actual needs.

2) Relevant Equipment: Multimedia equipment is required during college class; moreover, it helps show betterment with translation technology consisting of corpus, term bank, online dictionary, and search engine and chatting software. Humans have already entered into ubiquitous computing epoch, not only teachers but also students should put a pairing of modern technique and translation teaching into combination normally. The improvement on information skill is also involved in the concept of adaptation in eco-translatology.

\section{B. Organization of College Translating Class}

1) Teaching Purpose: The main task in teaching design is to set up a teaching purpose, because that it is the foundation and according to course execution. Eco-translatology holds a view that every eco- subsystem is interactive, thereby, translating behavior influences a series process, such as listening, reading, speaking, writing and so on in college studying. The basis and principal part are the language using ability and language potential ${ }^{[9]}$. So college translating course also should consider translation into a complex and harmonious organization instead of simple point-to-point translation. Ability-improvement should be teaching purpose in college translating class.

2) Teaching Content: Translation course ought to form module system including language basic module which aims to increase student's diglossia ability and eliminate negative 
transfer of mother tongue ${ }^{[7]}$, translation theory and practice module which makes students comprehend translating procedure in cognitive way, and expansion module which cultivates students' critical thinking ability and cognition.

\section{EVALUATION STANDARD}

It is an indispensable part to stress on the progress and translating subject-orientation in eco-translatology college teaching system. Translation refers to a non-linear procedure under uninterrupted research. College students should be encouraged to interchange roles from translators to appraisers. Inspired by teachers, students should select words and meanings with adaptation, and operate rewriting throughout every phase of translation in class. If it is usual practice, after discussion with teachers or partners, the unqualified translated text should be eliminated through the standards of adaptation and selection theory. As if there is a semester examination, the final scores in translation part would be recognized as evaluation or punishment. Evidently, all of these behaviors and performances are the consequence of choosing and punishing adopted by rules of "survival of the fittest", a piece of natural law in eco-translation environment.

To stress dynamic state and balance refers to emphasize the interaction between translating subject and external ecoenvironment in order to reach the ideal situation which is called dynamic balance. According to the theories of ecotranslatology, the relationship between teachers and students should shift from solely teach and learn to equivalent interaction among principal parts in translating class. The diversity and unity stand for paying attention to individuals' specific characters and generality commonness. Consequently, college English translating teaching should help perceive translating practice and theory, at the same time, focus on students' individual distinction. Under the framework and perspective of eco-translatology, translating strategies not only instruct the issue that how to translate words and phrases, but also interpret the thinking way and mentality in macro view.

\section{REFERENCES}

[1] Gutt, E-A. Translation and Relevance: Cognition and Context [M]. Manchester: St. Jerome Publishing, 2000.

[2] Hatim, B. Teaching and Researching Translation [M]. Edinburgh Gate: Pearson Education Limited, 2001.

[3] Hu, G. S. Translation as Adaptation and Selection [J]. Perspectives: Studies in Translatology, 2003 (4): 283-291.

[4] Hu, G. S. Eco-translatology: A New Paradigm of Eco-translation: A Comparative Study on Approaches to Translation Studies and a Brief Response to Some Related Questions/Doubts [J]. Foreign Language of China, 2014(5): 104-111.

[5] Katan, David. Translating Cultures [M]. Manchester: St. Jerome Publishing, 1999.

[6] Krohne, T. David. General Ecology [M]. Brooks/Cole: Thomson Learning, 2001.

[7] Munday, J. Introducing Translation Studies: Theories and Applications [M]. London: Routledge, 2000.

[8] Nida, E. Language, Culture, and Translating [M]. Shanghai: Shanghai Foreign Language Education Press, 1993.

[9] Phillipson, Robert. Book Review [J]. Language Policy, 2006 (5): 227232.

[10] Wang Jianna, Study on Teaching Mode of English Major Interpretation Under Framework of Eco-translatology [J]. Research in Teaching, 2015(6): 60-63. 